\title{
An overview of the energy scenario and energy storage device
}

With demand for the natural resources exceeds a certain threshold, it leads to a global ecological threat like the "Amphhan" catastrophe that had ravaged the eastern part of West Bengal during the month of February 2020 that resulted in the loss of lives and economic activity which is yet to be regained with its earlier momentum. The inflicted calamity has given a "blow" as well as "boost" to renewable energy sector that leads to greater seriousness on development of the energy storages devices/stations in the country. While India has already achieved 374 GW of total installed capacity of power generation in which the contribution from the thermal sector is about 62 per cent and that of the RP is about 22 per cent that comes to $90 \mathrm{GW}$ as of today and $60 \mathrm{GW}$ is under pipeline or under construction or under tendering process.

The year 2020 is undoubtedly a year of change and the COVID-19 pandemic situation together with enforced lockdown in several parts of the country and even in globe has forced people to think differently to remain relevant against the New-Normal.

In order to choose the sources of energy that does not cause pollution to the surrounding environment, the RET is the best and most favourable options to opt for along with the battery storage devices for making the power available throughout the day-long and even when the sun sets. Most of the batteries currently produced and used in our country is lithium-ion based and is mostly imported. To be on the self-reliant mode and moving towards "Atmanirbhar Bharat" through "Make in India" we need to have more and more indigenous manufacturer of Li-ion batteries. Good news is that 10 Indian companies have already procured manufacturing technology from DRDO and large scale production of indigenous Li-ion batteries is expected soon.

The National Energy Mission of the Government of India has just rolled out with a focus on the Make in India and is envisioned to take all necessary formalities and policy decisions to be adopted to incentivise advanced energy

Messrs. Amar Nath Bhadra, FIE, Dy. Director of Boilers (Retd), Government of West Bengal, Kolkata, and Subhendu Podder, FIE, Partner-Energy \& Environment, Indus Energy Consultants LLP, New Delhi, India. E-mail: amarnathhow@yahoo.com / psoddersp@gmail.com storage manufacturing in India through the application of innovation and new technology options that are available. As a science communicator, the authors strongly opine that with the appropriate support from the Government of India through the policy decisions by the Niti Aayog, India will be one of the top markets for the energy storage adoptions and manufacturing and is another way forward to mitigate the climate change by producing electricity free from carbon dioxide emissions into atmosphere and provide green energy for sustainable path of development.

As we see that the energy storage is a new thrust area along with introduction of FGD technology retrofitting with the thermal power plant, we look forward to the new ecosystem to be achieved by 2030.

Keywords: Make in India, RET, Atmanirbhar Bharat, DRDO, Niti Aayog, Li-ion, and FGD.

\subsection{Introduction}

$\mathrm{T}$ The growth of a nation and its key economic activities is directly proportional to the growth of power sector, as it facilitates development across various sectors of the economy, such as manufacturing, agriculture, commercial enterprises and railways. The growth of power sector takes a leap after the enactment of Electricity Act 2003 which has brought in revolutionary changes in almost all the areas of the sector. This has led to significant investment in generation, transmission and distribution areas. About 98.2\% villages have been electrified. Regional grids have been integrated into a single national grid, facilitating free flow of power from generating point to consumption point. All India peak demand (MW) and energy (MU) shortage have registered a steady decline to as low as $3.2 \%$ and $2.1 \%$ respectively. However, overall capacity utilisation has come down to as low as $42 \%$, which is a matter of concern.

\subsection{History recall}

During the initial few years after independence the growth and development of power sector were mainly shouldered by the central and state governments. Those days were of days of huge shortages of generation/supply and widespread loadshedding. All the state governments were struggling to match the growth of electricity generation with the growth of 
demand. Utility companies within the state used to spend considerable energy in devising/formulating a power-cutschedule to offer more and more predictability, as a measure of service quality. More and more funds were allocated to power generation projects both under state and central. In order to sustain the industrialisation process, industries were encouraged to install captive power plants. Government policies were simplified and modified to allow pumping of surplus power to the state-grid from those captive power plants. The Electricity Act 2003 came into force bringing about a wind of changes in the sector.

Encouraged by the policy incentives and facilitated by the Electricity Act 2003, a lot of projects have been initiated at the various parts of the country and a quantum jump on capacity addition noticed in the next few years. The total generation capacity increased from $100 \mathrm{GW}$ to $200 \mathrm{GW}$ till 2012 and to $300 \mathrm{GW}$ in next four years.

Government of India took complementary initiative of building sufficient transmission capacity and as a step in that direction all the regional grids have been connected to form a national grid in 2012. Additionally, Central Government has initiated augmenting transmission capacities by adopting more and more high to extra-high voltage transmission. The government is also encouraging private entrepreneurs to become a transmission licensee through participation in TariffBased-Competitive Bidding (TBCB) on Build-Own-OperateTransfer (BOOT) basis.

\subsection{Present scenario of generation}

The proportional mix of installed capacity [1], as of $31 \mathrm{st}$ March 2018, is as under:

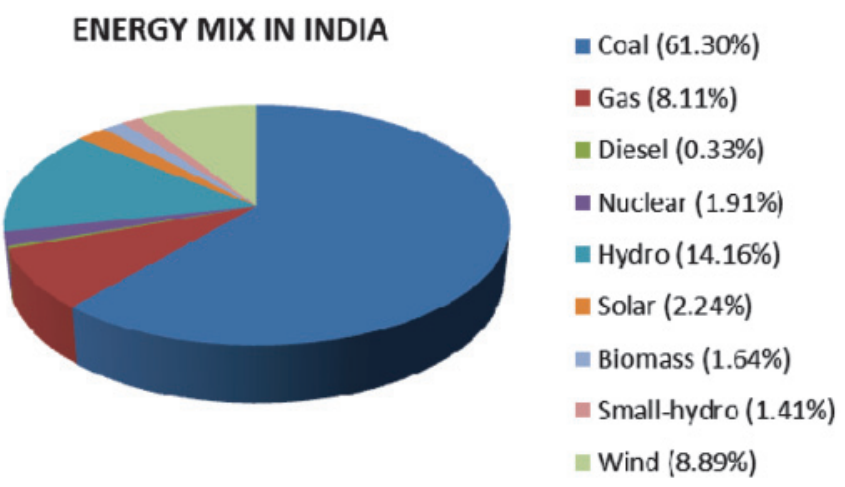

Fig.1 (Source wise percentage installed capacity)

In line with the long term vision of Government of India for promoting "Green Power" the country quadrupled its solar-generation capacity from 2,650 MW on 26 May 2014 to 12,289 MW on 31 March 2017[3]. The trend on the addition of solar power generation capacity in the last few years is shown in Fig.2.

\subsection{New norms - compliance issues}

Immediately after notification of the new environmental norms the Central Electricity Authority (CEA) and Regional Power
TREND OF SOLAR CAPACITY ADDITION

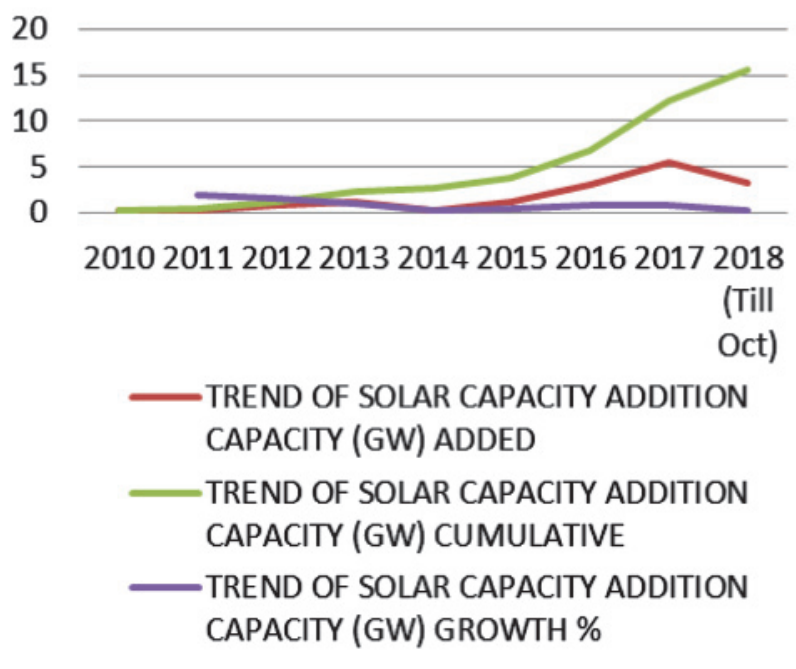

Fig.2 (Yearly trend of solar capacity addition)

Committees (RPCs), under the Ministry of Power (MoP), started discussions with the power producers, engineering consultants, manufacturers, erectors and other stakeholders are to formulate the most viable implementation plan without risking the availability of adequate number of generating stations till all the stations become fully complied. An analysis on the age and performance of the existing power station reveals that:

(i) Many power plants surpassed their useful life of 25 years.

(ii) Most of these old units are less than $110 \mathrm{MW}$ units.

(iii) As on March 31, 2017, the capacity of coal-based thermal plants that are more than 25 years old is approximately 39,296 MW.

(iv) These old units consume more coal, produce less power and are a major contributor to air pollution.

(v) PLFs of these plants can go below $40 \%$.

(vi) They have high auxiliary consumption as well.

A significant step has already been initiated by the Ministry of Environment, Forest and Climate Change (MoEF \& CC) through its notification mandating compliance of new norms regarding sulphur oxides (SOx), nitrogen oxides (NOx), mercury $(\mathrm{Hg})$ and water consumption norms.

\subsection{Future of coal based power}

The CEA has stated in the draft National Electricity Plan that no new coal based power plants are required in the country at least till 2027, other than the $50 \mathrm{GW}$ under-construction capacities. The country's peak power demand is projected to grow to $235 \mathrm{GW}$ in FY 2021-22 from $159 \mathrm{GW}$ in FY 2016-17 at a CAGR of $8 \%$. In the recently published draft National Power Policy, it has been presumed by CEA that the country has a 
surplus generation capacity and no further generation capacity in thermal needs to be added over and above the projects which are already in pipeline and expected to comeup within 2021.

India, having considerable longer spell of sunshine, has rightly focused on the aggressive development of solar sector. Solar being the non-schedulable nature of power, it should not be considered as the one and only replacement of coal generation.

India should not lose focus on all round development and do not put all its egg in one basket. The time has come to forcefully retire the small/old/inefficient/polluting units and allow the new and efficient units to run at its full capacity. Install or facilitate installation of supercritical and ultrasupercritical units and phase out the sub-critical units. This cycle should go on for the sustainability of the power sector in particular and the society as whole.

\subsection{Recommendations and conclusion}

There is no doubt that in India coal based thermal power will continue to be the major source of electricity but having committed to ensure sustainability of the environment and to ensure safe-living on earth without stalling the development process we need to continually research on the technology to reduce the GHG production from the coal based power stations. As the government is indicating to force retirement of the plants which will be non-compliant to the new environmental norms a policy should also be formulated to progressively switch to super-critical to ultrasuper-critical to advanced ultra-super-critical technology as a time bound mandate.

Leaders from the G20 nations were assembled in a conference in Saudi Arabia and have come up with the conclusion that in the face of COVID-19 pandemic situation affecting the entire Globe to spare no effort to supply COVID-19 drugs, testing kits, and to supply vaccine to the country both developed nations and developing nations. The COVID-19 pandemic and its impact on the economy is, causing great hardship in terms of livelihood is an unparalleled shock for the year 2020. The world's economy has been experiencing a larger shock that had been never experienced before and the G20 summit had planned to work in tandem so that dipped economy is recovered and booming at the earliest to provide reprieve for the people who lost their jobs.

We see a bright future is awaited before us as our government vowed to achieve the target of capacity addition of $175 \mathrm{GW}$ of RP by the end of the year 2022 and $450 \mathrm{GW}$ of the renewable power by 2030 to launch fight against the climate goal and to maintain ecological balance by more and more plantation of trees, which will ensure availability of a larger sink to absorb GHG released from the thermal power plants. Most importantly, the phasing out of the sub critical boilers being operational with various developers, including NTPC Ltd, to be ensured first which in turn also improve the operational flexibility of the balance thermal power plants even after injection of $175 \mathrm{GW}$ of solar energy in the national grid.

While observing that the second wave are more deadly that the first one climate change must be fought not in silos but in an integrated, comprehensive and holistic way. Inspired by our traditional ethos of living in harmony with the nature and the commitment of Government of India, has adopted a low carbon and climate based resilience practices while addressing in the G20 summit on the topic safeguarding the planet, the circular carbon economy approach.

The Prime Minister of India stressed on to single use plastics, to expand the forest cover, tiger and lion population be increased, mangrove forest in the delta belts zones in the Sunderban delta be made healthy as it protects external thrust and providing oxygen support for progression of life. In his key address recently he pointed out that increasing R\&D activities and innovation in new and sustainable technologies are the way forward for human survival on the planet earth.

The current ecosystem prevailing can progress faster if there is greater support of technology and innovation and finances to the developing world but has to have in a smarter approach.

Humanity to prosper, every single individual must prosper and to safeguard the planet earth we must use the green energy from the non-fossil fuel resources.

Atmanirbhar Bharat initiative together with Make in India will be able to address the challenges ahead as we promise to turn around the economy and to become a 5 trillion dollar economy by the year 2026 .

\subsection{Acknowledgements}

The authors deeply acknowledge the support and encouragement received from our family members, Mr. Anup Bhargava, an Independent Resolution Professional (IRP), for his constructive suggestions towards policy insight and the publisher who constantly encourages us to deliberate on these issues.

Faced with the daunting and unprecedented COVID 19 pandemic related challenges, the Indian power sector has been showing enough resilient to deliver the uninterrupted supply of power during the lock down and unlocking period for the last 11 months with the highest peak load demand of $176 \mathrm{GW}$ by the end of November 20. India will look to be innovative in its approach to garner additional investment of 1.75 crores for having another $60 \mathrm{GW}$ of the renewable power generation capacity by the year 2022 to meeting the

(Continued on page 198) 